\title{
Triboelectric charging of polyethylene powders: Comparison of same-material and different-material contributions to the charge build-up
}

\author{
L. Konopka a , S. Jantač ${ }^{\text {a }}$ M. Vrzáček ${ }^{\text {a }}$, M. Svoboda ${ }^{\text {b }}$ J. Kosek ${ }^{\text {a,b,* }}$ \\ a University of Chemistry and Technology Prague, Department of Chemical Engineering, Technicka 5, 16628 Prague 6, Czech Republic \\ ${ }^{\mathrm{b}}$ University of West Bohemia, Univerzitni 2732/8, 30100 Pilsen, Czech Republic
}

\section{A R T I C L E I N F O}

\section{Article history:}

Received 8 November 2019

Received in revised form 1 April 2020

Accepted 9 April 2020

Available online 11 April 2020

\section{Keywords:}

Powder charging

Triboelectric charging

Polyethylene

Unipolar

Bipolar

Agglomeration

\begin{abstract}
A B S T R A C T
The understanding of triboelectric charging of industrially important powders can help in avoiding or controlling the particle agglomeration and wall sheeting. We developed a new experimental approach to study both samematerial particle-particle $(\mathrm{P}-\mathrm{P})$ and different-material particle-wall $(\mathrm{P}-\mathrm{W})$ charging of nascent polyethylene (PE) particles born by catalytic polymerization. We constructed a simple tribocharger consisting of a metal box divided inside into several compartments filled with the PE sample and attached to the vibration shaker. The particle charge distribution was characterized by a self-constructed electrostatic separator. This way, we investigated the charging dynamics of PE particles colliding with other PE particles as well as with metal walls of the box compartments. Both $\mathrm{P}-\mathrm{P}$ and $\mathrm{P}-\mathrm{W}$ charging were measured either separately, or in sequence, and in combination of simultaneous $\mathrm{P}-\mathrm{P}$ and $\mathrm{P}-\mathrm{W}$. The different-material $\mathrm{P}-\mathrm{W}$ charging produced unipolarly charged particles and was much faster than the same-material $\mathrm{P}-\mathrm{P}$ charging leading to bipolar particle charge distribution.
\end{abstract}

(c) 2020 Elsevier B.V. All rights reserved.

\section{Introduction}

Although triboelectric charging can be utilized in several industrial areas like toners [1], mineral separation [2] and also plastics separation $[3,4]$, it is typically viewed as an undesired phenomenon that complicates pneumatic conveying of powders [5-7] and leads to particle agglomeration and fouling of devices [8-14]. Many industrially important products are delivered in the form of fine powders of typically insulator particles (polymers, drugs, food supplements, pigments, flour) and their charging can be very fast. On the other hand, the subsequent charge neutralization by, for example, air ions in systems of charged insulator particles in air can be very slow [15]. Effective methods for a quick discharge without the impairment of the product surface physically and/or chemically are difficult to find and realize. The addition of an antistatic agent is possible in some cases; however, this can lead not only to the increase of production costs, but it can also affect the product in an undesired fashion. Therefore, the understanding of the triboelectric charging itself appears to be a key in controlling the charge in dispersed particulate systems of insulators and in avoiding/lowering the consequent particle agglomeration or fouling of device walls and

\footnotetext{
* Corresponding author at: University of Chemistry and Technology Prague, Department of Chemical Engineering, Technicka 5, 16628 Prague 6, Czech Republic.

E-mail address: Juraj.Kosek@vscht.cz (J. Kosek).
}

plugging the conveyors by particles. Some current studies regarding electrostatic charging of powders are of little use for industry because:

- the system that undergoes charging doesn't resemble industrial conditions due to geometry (e.g., planar objects instead of particles), mode of friction or surrounding conditions,

- powder materials used in the studies have significantly different electric, mechanical and flowability properties than those typically used in industry (e.g., glass or silica particles or even beads instead of roughtextured particles [16]),

- the studies include either only different-material P-W charging or solely same-material $\mathrm{P}-\mathrm{P}$ charging, neglecting thus the simultaneous or consequent presence of both these types of charging in typical production/transportation processes.

Research team of professor Mehrani published an innovative series of experimental and modeling papers that focused on powder charging in small-scale or even pilot-scale systems including fluidization columns. The focus of these papers is primarily the different-material particle-particle and particle-wall charging, where fines of different materials carry some charge away from the bulk of relatively large polyethylene particles or glass beads $[17,18]$. The research group also reported that the bipolar charge was found on polyethylene particles that adhered to the column wall after fluidization $[13,19,20]$. Such finding 
indirectly indicates that same-material particle-particle charging appears in such systems. In this paper, we focus on the still missing comparison of contributions of the same-material particle-particle charging and the different-material particle-wall charging, as well as on the corresponding charging dynamics in systems with $\mathrm{P}-\mathrm{P}$ and $\mathrm{P}-\mathrm{W}$ charging that were studied separately, combined, and in sequence. The charging dynamics due to different-material particle-wall collisions for polyethylene powders was studied by Chowdhury et al. [21], who experimentally found the charging rate and the saturation charge value for a commercial LDPE particles - as a preparation for following modeling papers.

Regarding the modeling part, their model currently includes both $\mathrm{P}-\mathrm{W}$ and $\mathrm{P}-\mathrm{P}$ charging of PE particles in a fluidized bed with metal walls [22]. However, the P-P collisions in the model effectively only transfer the (unipolar) charge caused by $\mathrm{P}-\mathrm{W}$ collisions from the wall particles towards the particulate bulk. In other words, it appears that the same-material P-P collisions themselves don't produce a bipolar charge, similar to the models in $[23,24]$. Such description may be representative for the ideal case of systems of spherical particles of uniform size and exactly same material and surface properties (which is in the real case not achievable), but otherwise is in a contradiction with extensive experimental data regarding $\mathrm{P}-\mathrm{P}$ same-material charging.

Németh et al. [25] examined simultaneous $\mathrm{P}-\mathrm{P}$ and $\mathrm{P}-\mathrm{W}$ charging of several polymers in a fluidized-bed. In their case, the walls of the fluidization column were lined by the polymer under investigation and therefore the experiments represented simultaneous $\mathrm{P}-\mathrm{P}$ and $\mathrm{P}-\mathrm{W}$ charging of objects of the same material only. The contributions of $\mathrm{P}-\mathrm{P}$ and $\mathrm{P}-\mathrm{W}$ collisions to the charging were not evaluated.

Majority of the charging-related literature focuses on the different-material charging. As such, this kind of charging is relatively well understood in general. Specifically, the different-material charging is fully understood for metals and described by the underlying concept of material work function and contact potential formed on the interface of the metals in contact [26]. A similar concept of effective work function is then applied to insulator-metal charging [16,20,27]. However, the idea of effective work function isn't fully supported by a physical theory, as there are no free charge carriers in insulators. On the other hand, the concept of effective work function or contact potential works well for the description of charging, as its application in mathematical models is documented to fit well the experimental data. Both theory and experiments suggest that the friction between two different materials leads to the build-up of a positive charge on one material and a negative charge on the other one, where the negatively charged material is the one with a higher electron affinity. Such behavior is suggested also by the triboelectric series and is widely accepted at least for materials that are far from each other in the series.

Much less data can be found for the charging of objects (typically particles) made of nominally "same" material, as these are more difficult to measure. Therefore, literature studies include not only laboratory measurements, but also field observations of systems like sand particles in dust storms or soil particles in tornados or volcanos [28-31]. The same-material objects typically contain some sort of surface nonhomogeneity that is ultimately responsible for charge transfer during their contact. Such non-homogeneity can be of chemical or physical origin. Chemically-based inhomogeneity can be, e.g., the uneven oxidation of the material or the presence of impurities, whereas physically-based inhomogeneity can mean that only some electrons on the surface are significantly excited by radiation or even by the friction of the object against another one $[32,33]$. Such high-energy electrons present on the object surfaces can be transferred during objects collisions. And due to the charge conservation, any charge transfer in the enclosed system of the same-material particles will inevitably lead to bipolar charging - i.e., some objects (particles) will become charged positively and some other ones negatively. However, our understanding of the charging, in this case, is limited. In fact, it is still unclear whether the actual charge carriers are electrons, ions, or charged nanoscopic pieces of the material (attrition particles) [34-36]. Nevertheless, for the charging itself, the aforementioned implications hold true regardless of the origin of the charge carriers.

The crucial information missing in the literature is the comparison of same-material $\mathrm{P}-\mathrm{P}$ charging and different-material $\mathrm{P}-\mathrm{W}$ charging for a sample representing the industrially produced powder in terms of charging dynamics and specifically the evolution of particle charge distribution for the respective types of charging. Therefore, this paper carries out such experimental study.

\section{Methodology}

For our measurements, we constructed a simple tribocharger consisting of a metal box divided inside into 100 compartments. Some of the compartments were filled with PE particles, and the actual number of filled compartments or the amount of sample were modified depending on whether we wanted to preferentially observe $\mathrm{P}-\mathrm{P}$ or rather $\mathrm{P}-\mathrm{W}$ charging or the combination of both. The metal box was then attached to a shaking apparatus with well-defined frequency and amplitude of shaking and this way the sample was charged. Finally, the charged sample was separated in a self-designed electrostatic separator and we thus obtained particle charge distributions for all experiments. The relative humidity ( $\mathrm{RH}$ ) for all the measurements was $30 \%$ with the maximum (absolute) deviation of $\pm 3 \% \mathrm{RH}$. The only exception was a measurement that tested the repeatability of electrostatic separation of a pre-charged sample. In this case, the RH was not controlled (but was measured as 21\%), as we didn't focus on the charging process itself, but rather on the capability of the electrostatic separator. Relevant information about published experiments are given in Table 1 .

\subsection{Samples}

For all measurements in this paper, mid-density polyethylene (MDPE) particles with the density of $937 \mathrm{~kg} / \mathrm{m}^{3}$ were used (Fig. 1). Our results are presented for both the narrow and the nascent "broad" particle size distributions (PSD), respectively. The narrow PSD includes particles of $0.8-1.0 \mathrm{~mm}$ in diameter and the broad PSD contains particles of $0-1.2 \mathrm{~mm}$ in diameter and is shown in detail in Table 2. Broad PSD represents PSD of nascent PE as it is obtained from the industrial fluidized bed reactor.

\subsection{Triboelectric charging - shaking apparatus}

To study both particle-wall and particle-particle charging, we poured the sample of PE particles into an aluminum charging box with several compartments (Fig. 2). In most of our experiments, however, we removed the inner walls and varied the amount of sample poured into the metal box, by which we adjusted the $\mathrm{P}-\mathrm{P}$ to $\mathrm{P}-\mathrm{W}$ collision frequency. The size of the charging box was $20 \times 20 \times 4.2 \mathrm{~cm}$ and the size of each compartment was $2 \times 2 \times 4.2 \mathrm{~cm}$. After that, the box was enclosed and fixed to the shaking apparatus (originally sieve shaker

\section{Table 1}

List of experimental setups. Highly charged particles are those with the charge below - 30 $\mathrm{nC} / \mathrm{g}$ or above $+30 \mathrm{nC} / \mathrm{g}$.

\begin{tabular}{lllc}
\hline$\theta_{P P / P W}$ & Charging period (min) & \multicolumn{2}{l}{$\begin{array}{l}\text { Mass fraction of highly charged } \\
\text { particles }\end{array}$} \\
\cline { 3 - 4 } & & Negative & Positive \\
\hline 2.35 & 5 & 0.14 & 0.00 \\
5.57 & 60 & 0.92 & 0.00 \\
15.84 & 60 (broad PSD) & detailed results in section 3.4 \\
31.6 & 2880 & 0.19 & 0.10 \\
$\infty$ & 2670 & 0.17 & 0.11 \\
$5.57 \& \infty$ & 1575 (in sequence) & detailed results in section 3.5 \\
\hline
\end{tabular}




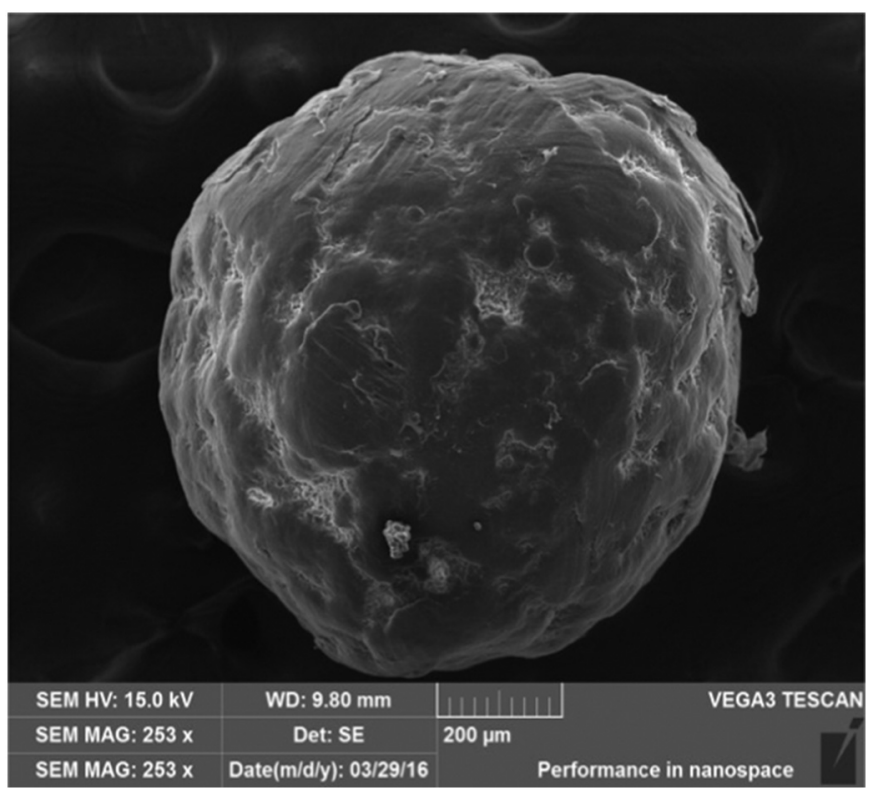

Fig. 1. Scanning electron microscopy image of a PE particle of the measured sample.

Table 2

Mass distribution of PE sample with a broad PSD.

\begin{tabular}{ll}
\hline Size fraction $(\mathrm{mm})$ & Mass fraction $(\%)$ \\
\hline $0-0.6$ & 10.98 \\
$0.6-0.8$ & 31.63 \\
$0.8-0.9$ & 32.66 \\
$0.9-1.0$ & 19.58 \\
$1.0-1.2$ & 5.15 \\
\hline
\end{tabular}

Retsch AS 200, shaking frequency of $50 \mathrm{~Hz}$, shaking amplitude up to 1 $\mathrm{mm}$, solely vertical vibrations) and grounded (Fig. 3).

Thereafter, the sample was shaken in the box for a defined period of time and thereby the sample was charged. In experiments focused on

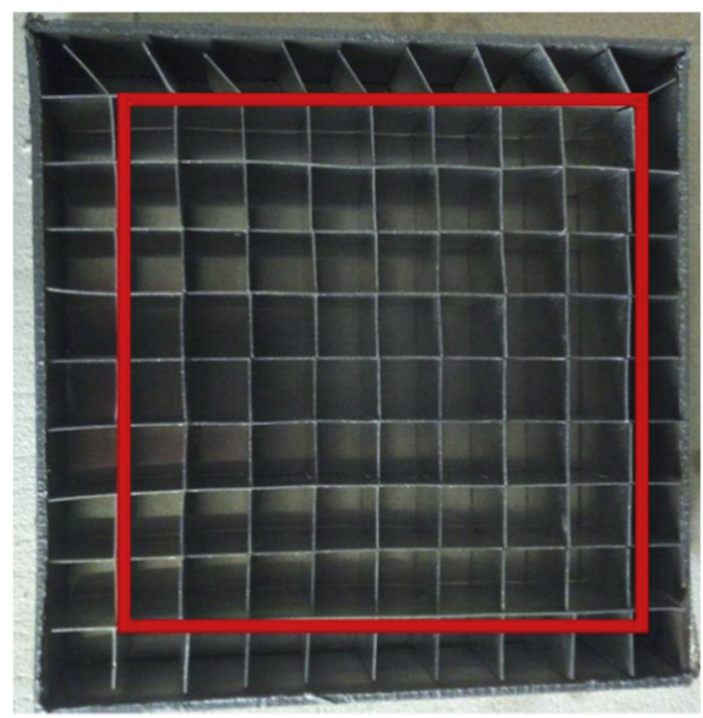

Fig. 2. Aluminum box with compartments. By controlling the number of compartments filled with PE sample and the mass of the sample, the ratio of $\mathrm{P}-\mathrm{P}$ to $\mathrm{P}-\mathrm{W}$ collision frequency is indirectly adjusted. The red square denotes a maximum usable area for defined charging (where walls are made solely from aluminum and shape of compartments is not significantly distorted). the charging of PE particles against the inner aluminum walls of the box, i.e., against the compartment walls, a small amount of sample was evenly distributed into each compartment. Thus, the collisions of particles with the walls were much more frequent than the ones with other particles and therefore the measured charge was attributed to $\mathrm{P}-\mathrm{W}$ charging. On the other hand, for the studies considering simultaneous $\mathrm{P}-\mathrm{P}$ and $\mathrm{P}-\mathrm{W}$ charging, relatively big amount of sample was placed only to a few compartments of the aluminum box so that both $\mathrm{P}-\mathrm{P}$ and $\mathrm{P}-\mathrm{W}$ types of collisions appear frequently, thus both types of charging are significant. Finally, in the case of particle-particle charging studies, the inner walls of the box were covered with PE particles; specifically, the particles of the same PE sample were glued by adhesive double-sided tape to the inner walls (Fig. 4). This procedure allowed to preserve properties of nascent PE. If we would form compact walls of PE trough melting of PE the internal and surface morphology would be changed.

\subsection{Estimation of $P-P$ to $P-W$ collision frequency ratio}

The estimation of the ratio of $\mathrm{P}-\mathrm{P}$ to $\mathrm{P}-\mathrm{W}$ collisions, $\theta_{P P / P W}$, was obtained with the use of a simple mathematic model written in Fortran programming language. In order to avoid the time-demanding integration of Newtonian equations of motion for each particle, the real system of shaken particles in the gravitational field was approximated by a system of spherical particles elastically colliding with other spherical particles as well as with the device walls with no external forces acting on them. The electrostatic forces were also omitted, therefore the model describes mainly the early stages of the shaking experiments, where the particle charges are low and don't significantly alter the particle trajectories. Due to such simplifications, the height of the simulated box had to be adjusted in order to represent only the 'active' height of the box, where particles were present. In our experiments, the particles were observed to 'jump' during the shaking approximately $1 \mathrm{~cm}$ above the level of the (previously still) layers of particles. Considering this and estimating the porosity of the layers of poured particles as 0.5 , the height of the simulation box was calculated. The other dimensions of the simulation box were set exactly as in the real case, i.e., 20 $\times 20 \mathrm{~cm}$ in the case of the whole box and $2 \times 2 \mathrm{~cm}$ in the case of a compartment. Thereby formed rectangular box was then evenly filled with particles of uniform velocities with random direction. The actual value of the particle velocity set to $1 \mathrm{~cm} / \mathrm{s}$ has no effect on the calculation of $\theta_{P P / P W}$ in this kind of model. After that, the volume fraction of particles $\varphi$ in the 'active' rectangular box was calculated. Once the particulate system was initiated, the 'pool-like' simulation of colliding particles followed.

The kind of model used in this paper is sometimes referred to as event-driven particle dynamics model and is described in detail in [37] or [38]. Therefore, the algorithm is described here only briefly. The three repeating governing steps of the algorithm are:

- Identify the earliest P-P or P-W collision,

- move all particles inertially until the earliest collision takes place,

- adjust the after-collision velocity of the colliding particle so that the kinetic energy and the momentum are conserved.

The model description in terms of equations follows. The collision of any two particles $i$ and $j$ of diameter $\sigma$, under the assumption that the particles move inertially until the collision takes place, happens when the following equation is met:

$$
\left|\boldsymbol{r}_{i j}+\boldsymbol{v}_{i j} t_{i j}\right|=\sigma
$$

where $\boldsymbol{r}_{i j}=\boldsymbol{r}_{i}-\boldsymbol{r}_{j}, \boldsymbol{v}_{i j}=\boldsymbol{v}_{i}-\boldsymbol{v}_{j}$ and $t_{i j}$ denotes the time necessary for the collision of the two particles. To account for both the positive and negative values of the expression in absolute value, Eq. 1 is squared and rearranged as: 


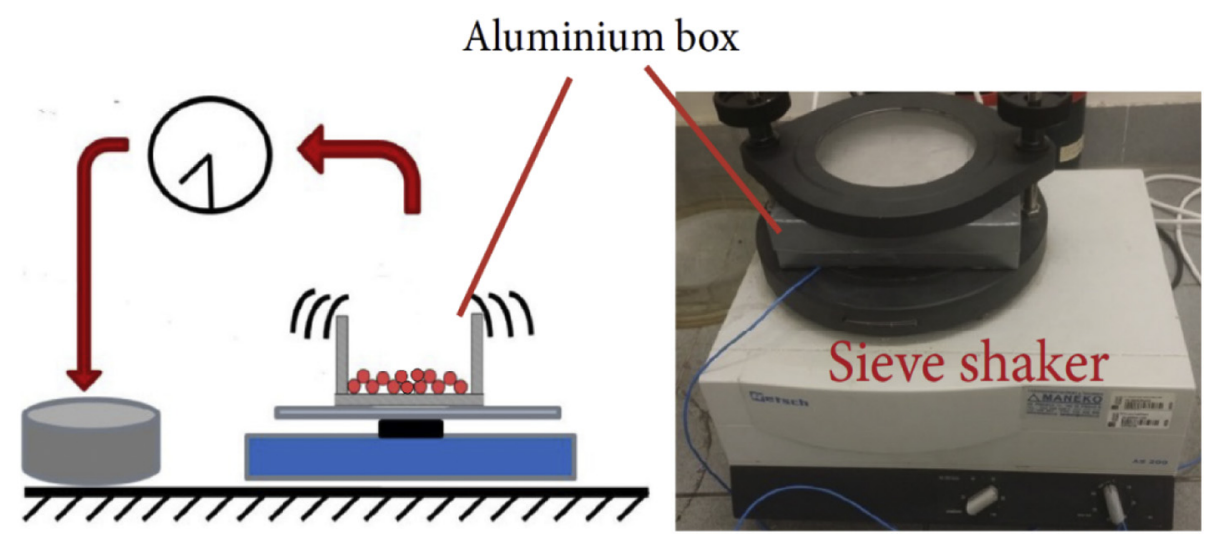

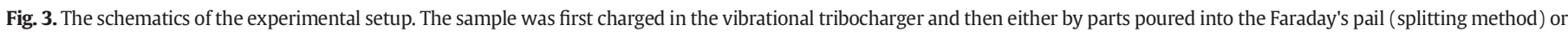
separated in an electrostatic field and then poured into the Faraday's pail (separation method).

$\boldsymbol{v}_{i j}^{2} t_{i j}^{2}+2 b_{i j}^{2} t_{i j}^{2}+\boldsymbol{r}_{i j}^{2}-\sigma^{2}=0$

where $b_{i j}=\boldsymbol{r}_{i j} \boldsymbol{v}_{i j}$. Because the particles aren't initially (as well as ever after) overlapping, which is carefully ensured by our particle filling algorithm, the collision time can be obtained if $b_{i j}<0$ and at the same time $b_{i j}^{2}-\boldsymbol{v}_{i j}^{2}\left(\boldsymbol{r}_{i j}^{2}-\sigma^{2}\right)<0$ as one of the positive real roots of the equation, specifically, the smaller one:

$t_{i j}=-\frac{-b_{i j}-\sqrt{b_{i j}^{2}-\boldsymbol{v}_{i j}^{2}\left(\boldsymbol{r}_{i j}^{2}-\sigma^{2}\right)}}{\boldsymbol{v}_{i j}^{2}}$

The collision time for each pair of particles is calculated this way and the minimum collision time $t_{p \text {, min }}$ corresponding to the particles that are about to collide earliest is found. Then, similarly, the time that it takes for each particle to collide with each wall is calculated, step-bystep for every wall that is perpendicular to $k$-th axis as:

$t_{i, k}=\frac{w_{k}-r_{i, k}-\frac{\sigma}{2}}{v_{i, k}}$

where $w_{k}$ represents the position of a wall perpendicular to the $k$-th direction. Only positive values of $t_{i, k}$ are accounted for when finding the

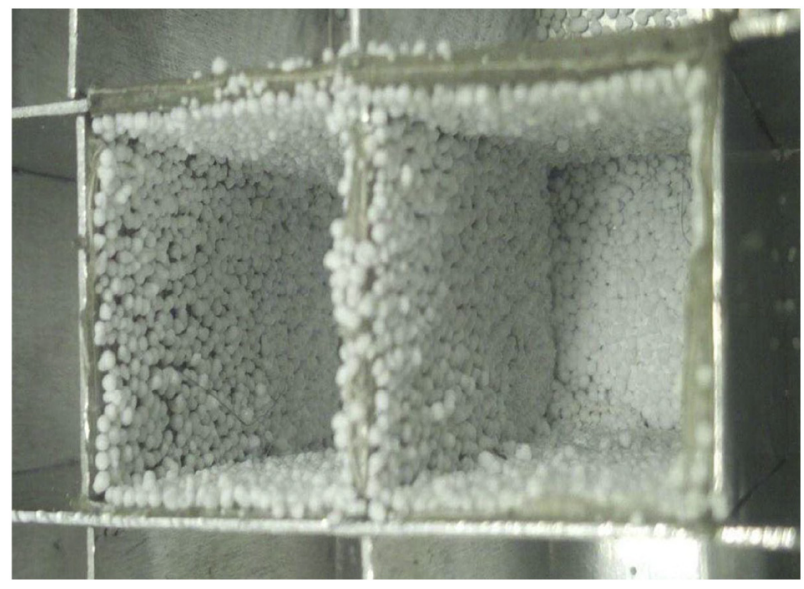

Fig. 4. Monolayers of PE particles were first glued to the inner walls of the aluminum box and then was PE sample poured inside. After attaching the box to the vibrational shaker, the charge caused solely by $\mathrm{P}-\mathrm{P}$ charging was observed. minimum. The minimum time, $t_{w, \min }$, corresponding to the $i$-th particle that collides with one of the walls $(k)$ the earliest is then identified.

After, the particles are moved inertially according to:

$\boldsymbol{r}_{i}=\boldsymbol{r}_{i, 0}+\boldsymbol{v}_{i j} t_{\min }$

where $t_{\min }$ stands for the lesser value of $t_{p, \min }$ and $t_{w, \min }$, and the subscript 0 represents the original state. Finally, the velocities of colliding particles are calculated. In the case that particle-wall collision appears first, the new velocity for the colliding particle is obtained by the change of the sign of the respective ( $k$-th) component of velocity, in the direction that is perpendicular to the wall that is in contact with the particle:

$v_{i, k}=-v_{i, k, 0}$

which represents fully elastic particle-wall collision. In the case that particle-particle collision takes place first, the new velocities for the two colliding particles are obtained using the conservation of total linear momentum and kinetic energy while assuming equal masses as:

$\boldsymbol{v}_{i}=\boldsymbol{v}_{i, 0}-\frac{b_{i j}}{\sigma^{2}} \boldsymbol{r}_{i j, \boldsymbol{0}}$

$\boldsymbol{v}_{j}=\boldsymbol{v}_{j, 0}-\frac{b_{i j}}{\sigma^{2}} \boldsymbol{r}_{i j, 0}$

The total numbers of $\mathrm{P}-\mathrm{P}$ and $\mathrm{P}-\mathrm{W}$ collisions, respectively, were recorded and $\theta_{P P / P W}$ was then calculated as their ratio. The $\mathrm{P}-\mathrm{W}$ collisions with the top wall were, of course, not accounted for, because the top wall served only to cut out the 'active' volume where the particles could realistically appear and such wall wasn't present in our experimental setup. Due to the initial setup of the particulate system and a certain level of inherent randomness, the value of $\theta_{P P / P W}$ showed evolution and stabilized typically after 5 million collisions in total.

Although the described model and some of its parameters are approximative, the model is certainly capable to demonstrate that some particulate systems (analogous to the real ones) prefer one type of collisions, e.g., $\mathrm{P}-\mathrm{P}$ over $\mathrm{P}-\mathrm{W}$. An estimation of $\mathrm{P}-\mathrm{P}$ to $\mathrm{P}-\mathrm{W}$ collision frequency ratio $\theta_{P P / P W}$ could thus be relatively cheaply obtained for particulate systems of hundreds of thousands of particles, as it was in our case. For the broad PSD system (Table 1), the estimate of collision frequency ratio was obtained from the simulation of a system of uniform spheres of $0.774 \mathrm{~mm}$ in diameter, which was the mean particle diameter. 


\subsection{Measurement of particle charge distribution}

To obtain the charge distribution of the sample charged in the shaking apparatus, the high-voltage electrostatic separator was utilized (Fig. 5 ). The separator consists of two counter-electrodes and twelve collector boxes enclosed in plexiglass and wooden construction. The charged particles were poured in between the electrodes ( $6-24 \mathrm{kV}$ potential difference) and separated by the electric field (up to $240 \mathrm{kV} / \mathrm{m}$ ) into the twelve collector boxes according to particle charge-to-mass ratio. In the end, the sample found in each collector box was poured into Faraday's pail (JCI 150), connected to electrometer (JCI 178), and its charge was measured. Last, to yield the PSD in each collector box and corresponding mass fractions, the sample from each collector box was additionally sieved and each fraction was weighted.

We developed a simple model to show the capability of the electrostatic separator to separate particles according to their charge density. Firstly, we utilized the FVM model provided in program electrostaticFoam to calculate the electric field in the separator. Then, we calculated the trajectories of the charged particles inside the discretized electric field via second Newtons law of motion. We considered 3 acting forces: Newtonian drag force for spherical particle, gravitational force and electric force. Results of the model prediction and experimental data show minor errors (Fig. 6). Because the intensity of the electric field is low and residence time of particles is short, the field charging of particle plays a minimal role.

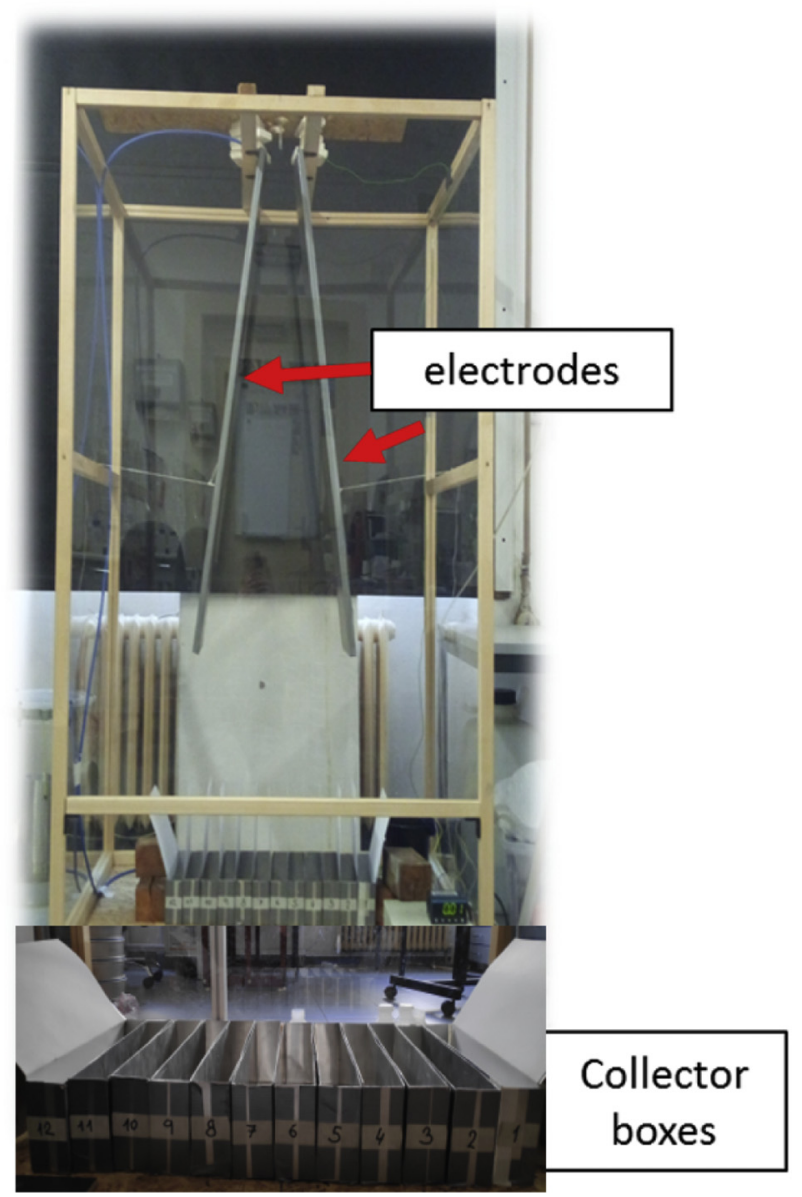

Fig. 5. The sample was poured between the electrodes of the electrostatic separator and particles separated by their charge-to-mass ratio were collected in collector boxes. After, the total charge of each box was measured. For broad PSD sample, the particles found in each collector box were also sieved.
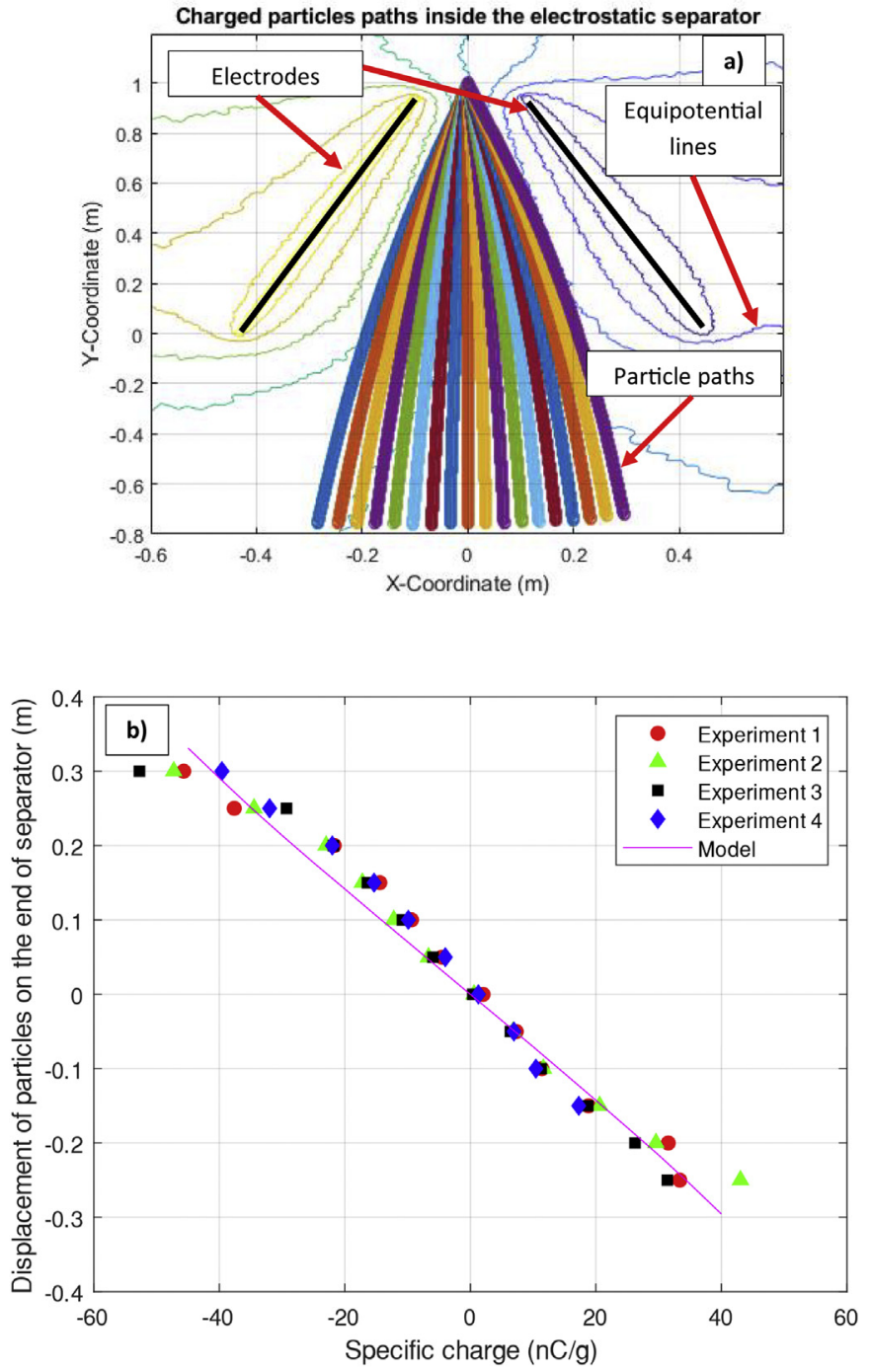

Fig. 6. A) The figure shows equipotential lines in the separator, the roughness of lines is caused by the coarse discretization. Additionally, the paths of charged particles are drawn. B) comparison of model prediction with experimental data.

\subsection{Reproducibility of measurements}

Although we believe that the consistency of our results itself may be the best sign of a good reproducibility of our measurements, we also provide the results of repeated measurements of charge distribution in order to further support such claim. Specifically, Fig. 7 shows three repetitions of charging cycles consisting of: (i) charging of $5 \mathrm{~g}$ of a fresh sample enclosed in the metal box with no inner partitions for 5 $\min \left(\varphi=0.013, \theta_{P P / P W}=2.35\right)$, (ii) separation of the sample in the electrostatic separator, and (iii) measurement of charge of particles in each collector box by the Faraday's pail. It is useful to note that the error of our method of charge distribution evaluation is even smaller than reported in Fig. 7 because our samples typically differ slightly in the total initial charge and charge distribution.

Fig. 8, on the other hand, depicts only the error caused by the separation of the sample and the subsequent manipulation during the charge measurement. Thus, contrary to Fig. 7, the measurement procedure represented in Fig. 8 hasn't involved the charging. It was obtained by the repeated separation and the subsequent charge measurements of one initially pre-charged sample. Specifically, $10 \mathrm{~g}$ of a fresh sample was charged in the metal box with no inner partitions $\left(\varphi=0.025, \theta_{P P / P W}=\right.$ 5.57) for $10 \mathrm{~min}$ at $21 \% \mathrm{RH}$. 


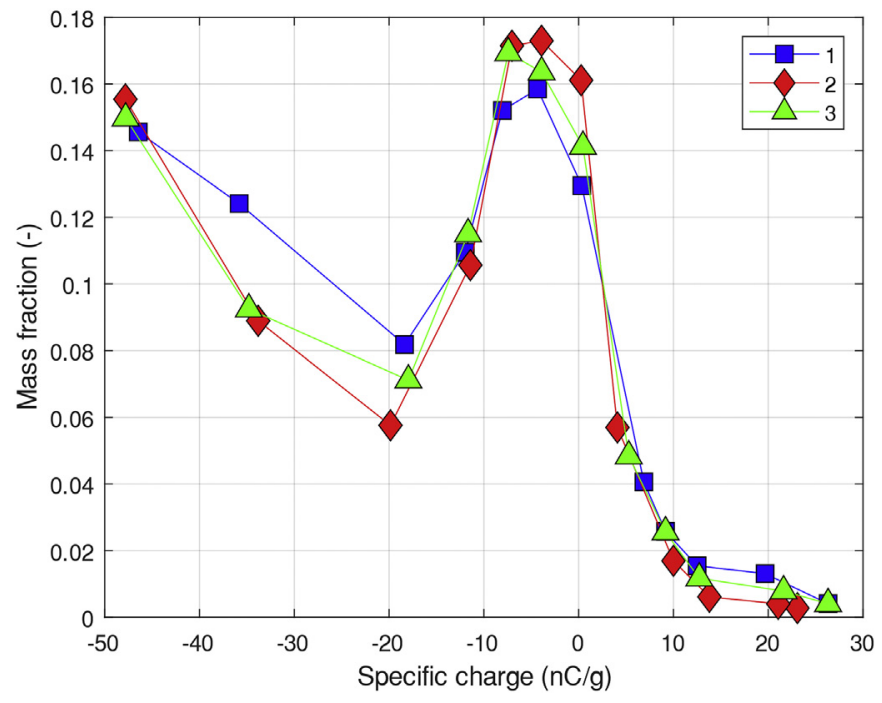

Fig. 7. Three charge distribution curves obtained by performing the whole charging cycle, i.e., charging, separation and charge measurement, each time with a fresh sample.

\section{Results}

In this section, we first present the results of charging dynamics of PE samples charged either solely by particle-particle or solely by particle-wall collisions, respectively, and then we describe the charging of the samples due to the combination of both types of collisions acting simultaneously. In the results we carefully differentiate between the cases of broad PSD and narrow PSD of PE sample. To understand the interaction of the two types $(\mathrm{P}-\mathrm{P}$ and $\mathrm{P}-\mathrm{W})$ of charging, we conducted also the subsequent charging of the sample first by $\mathrm{P}-\mathrm{W}$ collisions, followed by $\mathrm{P}-\mathrm{P}$ collisions and then again by $\mathrm{P}-\mathrm{W}$ collisions.

\subsection{Comparison of separation and splitting methods}

Fig. 9 shows the development of charge after 40 min of shaking of narrow PSD polyethylene sample. The two bottom lines represent the net charge and estimated charged distribution (vertical lines) in the system with a low volume fraction of particles in the charging box, i.e., $5 \mathrm{~g}$

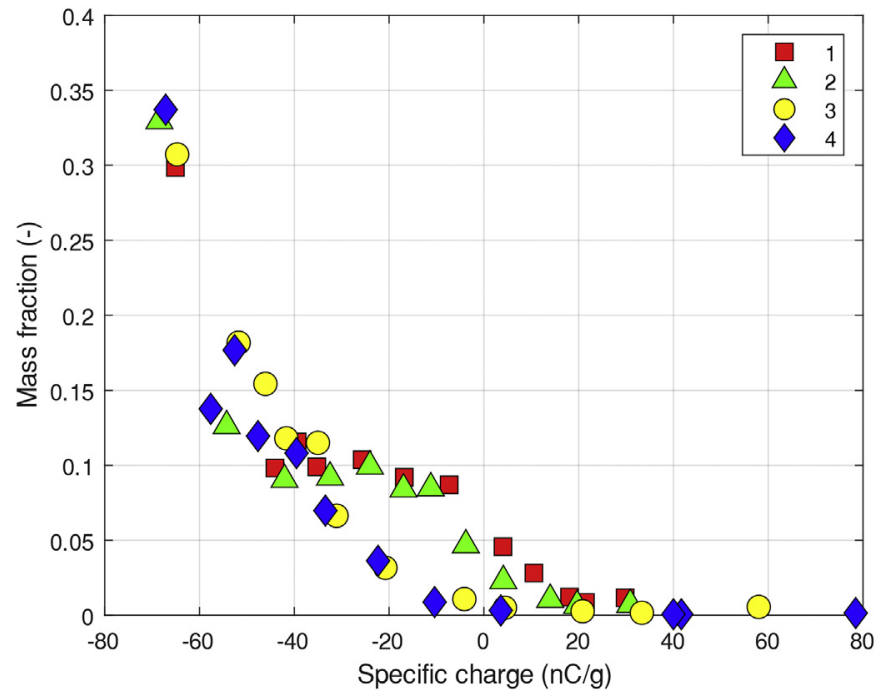

Fig. 8. Charge distributions obtained by four repeated separation and subsequent charge measurements of one initially pre-charged sample.

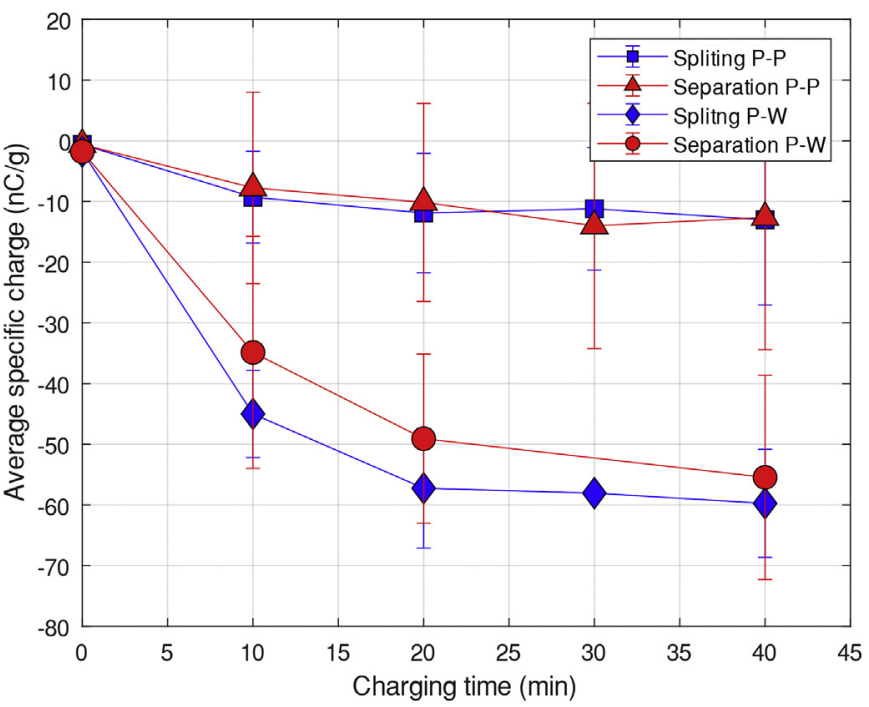

Fig. 9. The charge evolution of dense (top lines, $\mathrm{P}-\mathrm{P}$ dominated) and diluted (bottom lines, $\mathrm{P}-\mathrm{W}$ dominated) systems, respectively. The blue and red lines correspond to the charge measurements utilizing splitting and separation methods, respectively. Vertical lines show a standard deviation of data.

of sample charged in the whole box without inner walls $\left(\varphi=0.013, \theta_{P P /}\right.$ $P W=2.35$ ), and thus significant $\mathrm{P}-\mathrm{W}$ charging. Whereas the two top lines correspond to a system of bigger particle volume fraction in the charging box with compartments, i.e., $5 \mathrm{~g}$ of the sample in only 3 compartments, and thus also significant $\mathrm{P}-\mathrm{P}$ charging $\left(\varphi=0.235, \theta_{P P / P W}\right.$ $=11.94)$. Both systems tended to charge negatively, however, the system with bigger particle fraction charged more slowly because only part of collisions was with the aluminum wall. Thus, in such case, particles undergone mostly particle-particle collisions and therefore produced almost no net charge, as shown in Fig. 9. The blue and red lines correspond to two different methods of charge measurement after tribocharging in the vibration shaker. The red lines in Fig. 9 were obtained by charging the PE sample in the shaker and by further separation of the sample in the electrostatic separator into several collector boxes according to particle charge-to-mass ratio and measuring the charge of each box thereafter. On the other hand, the blue lines represent the charge measurement by splitting method, which is the less accurate method that doesn't require separator and is sometimes used in the literature for charge distribution estimation. In the splitting method, the charge measurement is sequential. Specifically, the charged sample is simply split into several parts and each part is poured into Faraday's pail separately and the charge of each part is measured. The obtained data then provide some information not only about the total charge but also about the approximate variation of the charge within the sample. Our results show that these two methods provide similar mean values of the measured charge, however, the splitting method has a lower variation of the data. Such lower variation, in this case, means that the splitting method is less sensitive, in terms of charge distribution, than the separation one, as it is unable to represent the charge distribution accurately to the extent that it doesn't detect bipolar charging in the case of the dense system (the two top lines), which is clearly demonstrated only by the separation method. It follows that for a system, where solely $\mathrm{P}-\mathrm{P}$ charging takes place, the difference in the accuracy of the two methods would increase even further. Taking into account that the utilization of electrostatic separator significantly increases the amount of information about charge distribution (Fig. 9) at the cost of only minor errors in charge measurements (Fig. 8), we consider the choice of the separation method to be justified. Thus, the separation method alone was utilized in all other measurements presented in this paper. 


\section{2. $P-W$ charging dynamics}

To study the charging of PE particles with narrow PSD 0.8 to $1.0 \mathrm{~mm}$ in diameter against aluminum walls, we placed $10 \mathrm{~g}$ of PE sample into the grounded aluminum box with no inner walls attached to the shaking tribocharger. The volume fraction of the particles was relatively low $\left(\varphi=0.025, \theta_{P P / P W}=5.57\right)$ and therefore the contribution of particle-particle collisions to charging could be neglected and the charging was in this case considered solely as particle-wall charging. After the charging, the sample was separated in the electrostatic separator into 12 collector boxes and the charge in each box was measured. This way, the particle charge distribution in the charged sample was obtained (Fig. 10). Our results show that the collisions of PE particles with aluminum wall lead to practically unipolar (negative) charging. Moreover, the variation of the charge within the sample gets narrow with increasing charging time, which suggests that the system reaches its saturation charge. In fact, we can show that after 60 min of charging, most particles are significantly charged to a negative charge (Fig. 11).

\section{3. $P-P$ charging dynamics}

To measure the charging caused solely by particle-particle collisions, we first glued monolayer of PE particles to the inner walls of the metal box in a way that the monolayer of particles prevented other particles from a contact with the aluminum wall and then we performed the charging experiment in 8 corresponding compartments of the box formed by the particle-covered walls. In this case, however, we used $20 \mathrm{~g}$ of the sample $\left(\varphi=0.286, \theta_{P P / P W} \rightarrow \infty\right)$ in order to increase the precision of the evaluation of charge in each collector box, because the error of the charge measurement unit decreases with the increasing amount of charge in the Faraday's pail. Our results show a clear tendency of the particles to charge bipolarly (Fig. 12) in contrast to P-W charging (Fig. 10) where the particles charged unipolarly. According to the charge conservation, the total charge in the system must theoretically remain zero for initially uncharged isolated systems, but we can observe a drift in the total charge to the negative end due to the manipulation with the sample. During the manipulation, the bipolarly charged particles touch aluminum collector boxes and aluminum Faraday's pail and this leads to the addition of the net negative charge to the system. Besides the bipolarity of charge, also the charging rate for $\mathrm{P}-\mathrm{P}$ charging appears to be much slower than the one for $\mathrm{P}-\mathrm{W}$ charging (Fig. 13).

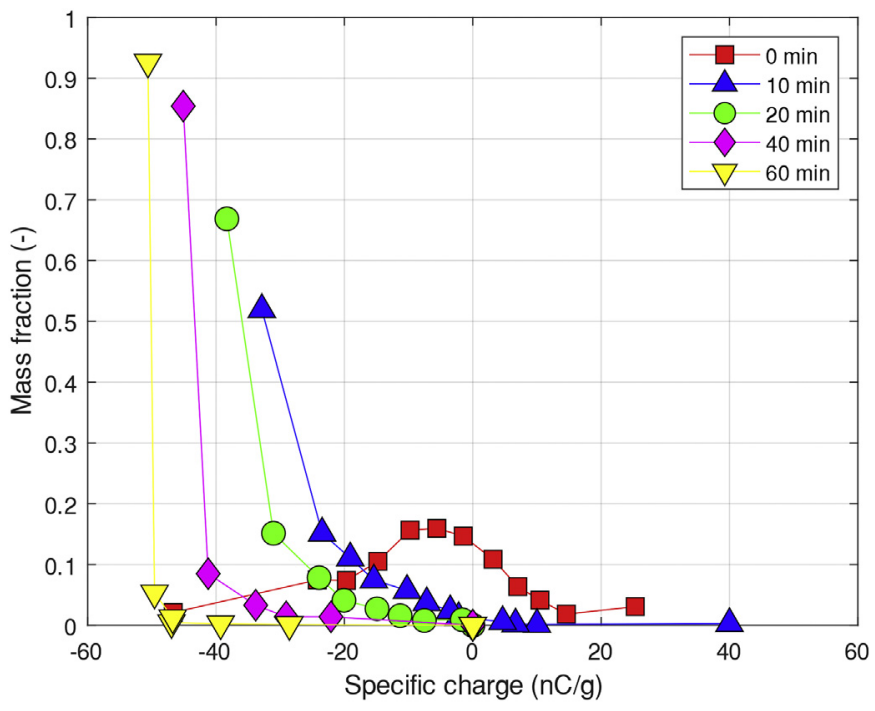

Fig. 10. The evolution of charge distributions for a diluted system of PE particles involved almost exclusively in $\mathrm{P}-\mathrm{W}$ charging. After $60 \mathrm{~min}$ of charging, the system approached its saturation state.

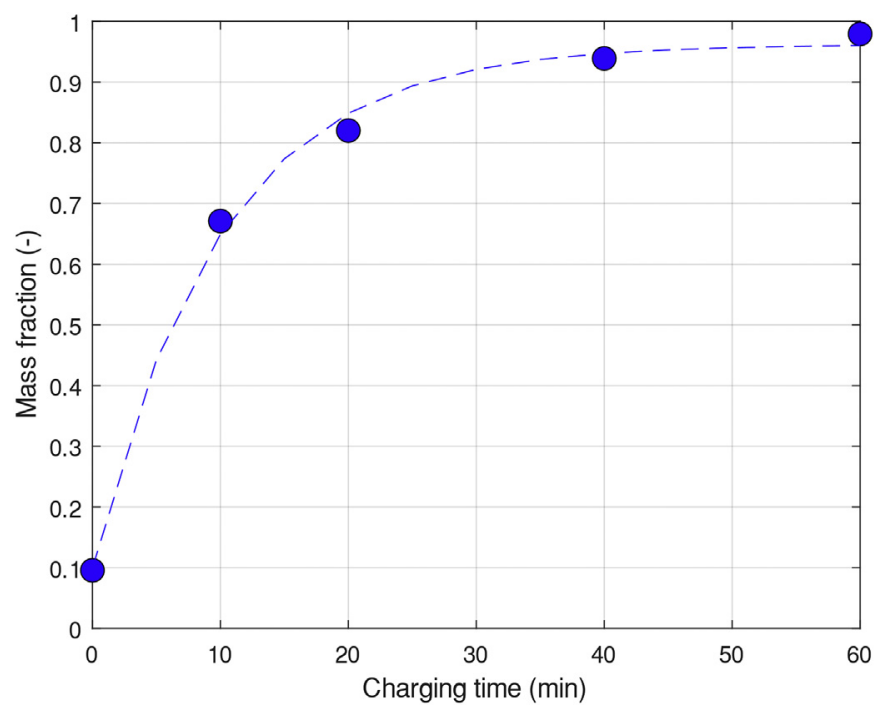

Fig. 11. The evolution of negatively charged particles (at least to $-30 \mathrm{nC} / \mathrm{g}$ ) during $\mathrm{P}-\mathrm{W}$ charging. An offset exponential fit was used; the equation can be derived from the work of Matsusaka [39].

Such an observation is most apparent in Fig. 14, where we show longterm evolution of the positive peak of bipolar charge distribution, i.e., the biggest positive value of charge after a respective period of charging that corresponds to the charge of particles found in the outermost collector box on the positive end. Such positive peaks were certainly caused by $\mathrm{P}-\mathrm{P}$ charging, not by manipulation. Considering the available literature, Németh et al. [25] in their measurements observed no significant bipolar charging of PE particles against other particles and a PE wall. However, the charging time in their study was at most $15 \mathrm{~min}$, which is shown to be insufficient to develop significant bipolar charge distribution.

\subsection{Combined $P-P$ and $P-W$ charging dynamics and the effect of PSD}

To observe the mixed effects of $\mathrm{P}-\mathrm{P}$ and $\mathrm{P}-\mathrm{W}$ charging, we charged $80 \mathrm{~g}$ of a narrow PSD sample in the whole charging box without inner walls and then separated the sample in the electrostatic separator and

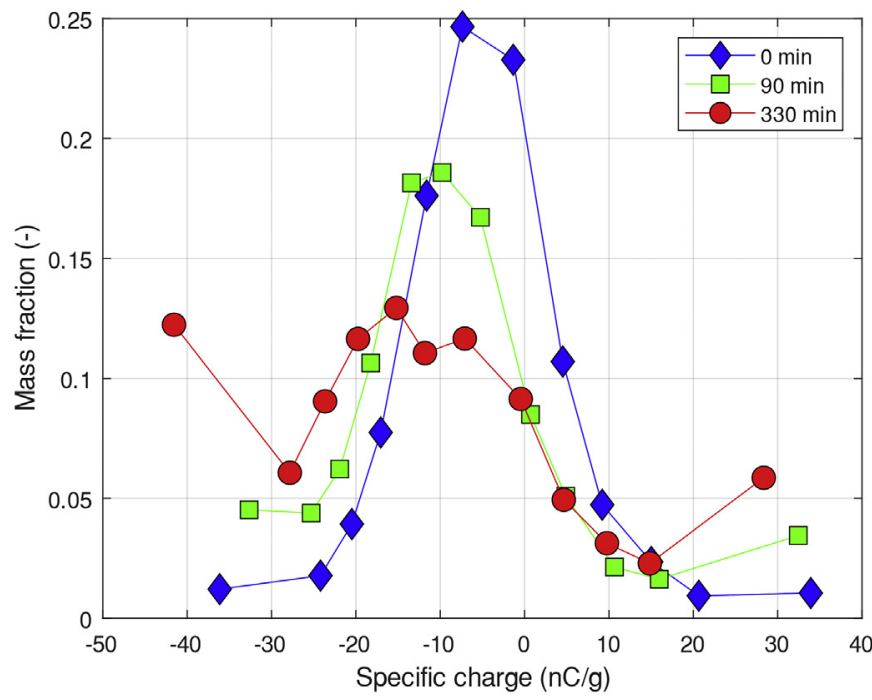

Fig. 12. The evolution of charge distributions for a system of particles involved almost exclusively in $\mathrm{P}-\mathrm{P}$ charging (with the exception of sample manipulation). 


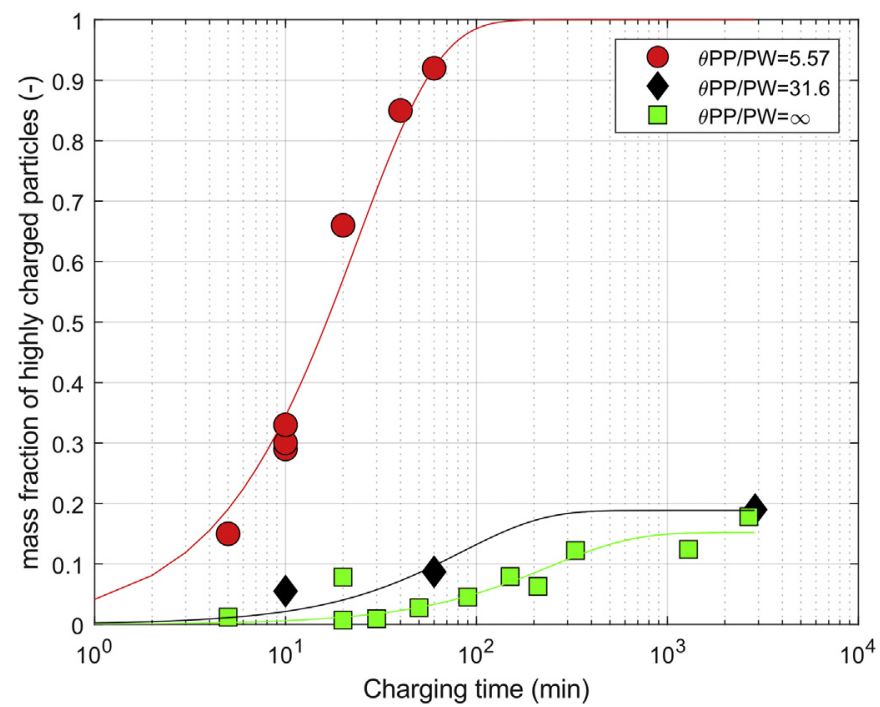

Fig. 13. Comparison of charging dynamics for various $\theta_{P P / P W}$, for negative polarity. Particles which charge density is lower than $-30 \mathrm{nC} / \mathrm{g}$ are considered highly charged.

measured the charge and mass of each collector box. This way, we obtained the mildly dense system $\left(\varphi=0.157, \theta_{P P / P W}=31.6\right)$ that involved both $\mathrm{P}-\mathrm{P}$ and $\mathrm{P}-\mathrm{W}$ charging. Fig. 15 shows this in terms of the evolution of the charge distribution of the sample. At first, the charging was solely unipolar and negative due to the $\mathrm{P}-\mathrm{W}$ collisions (see Fig. 10), however, after a long period of charging, the effect of the relatively slow $\mathrm{P}-\mathrm{P}$ charging was apparent and bipolar charging was observed as a result. Such result either suggests that $\mathrm{P}-\mathrm{P}$ charging dominates over the $\mathrm{P}-\mathrm{W}$ charging in a long run, or that after more than $60 \mathrm{~min}$ of charging the particles near the walls obtained a significant charge, fouled the walls and zoned out other particles from further $\mathrm{P}-\mathrm{W}$ collisions. We suspect that the second explanation is correct, because when we removed bulk particles from the system right after the charging, a monolayer of charged particles was observed (Fig. 17). The second explanation is supported also by the fact that the peak of uncharged particles near the middle of the charge distribution shifted more towards the zero charge value near the end of the charging. Such a shift could be contributed to the possibility that the negatively charged particles after

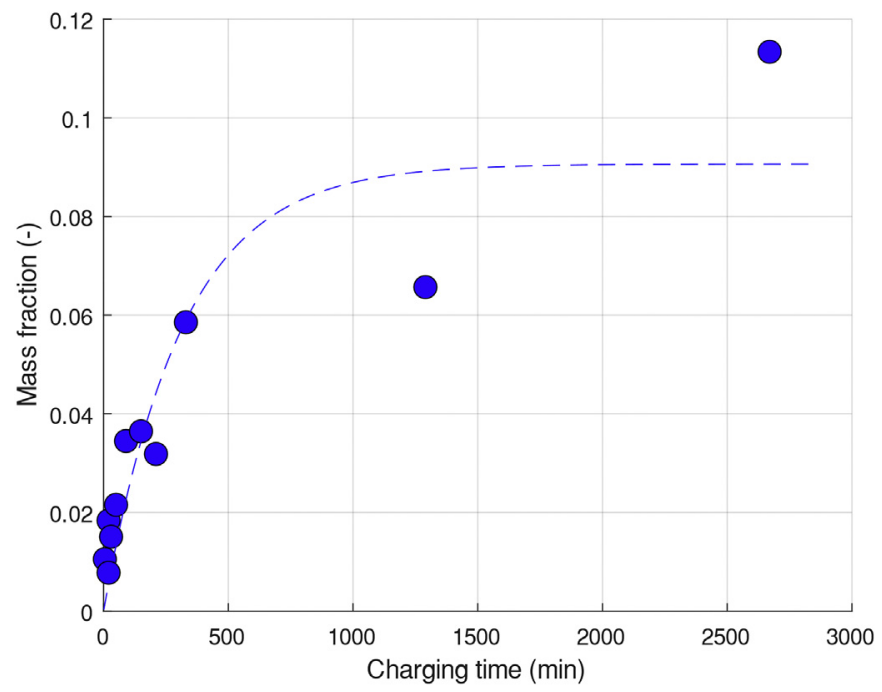

Fig. 14. The evolution of positive peak of the charge distribution for $\mathrm{P}-\mathrm{P}$ charging.

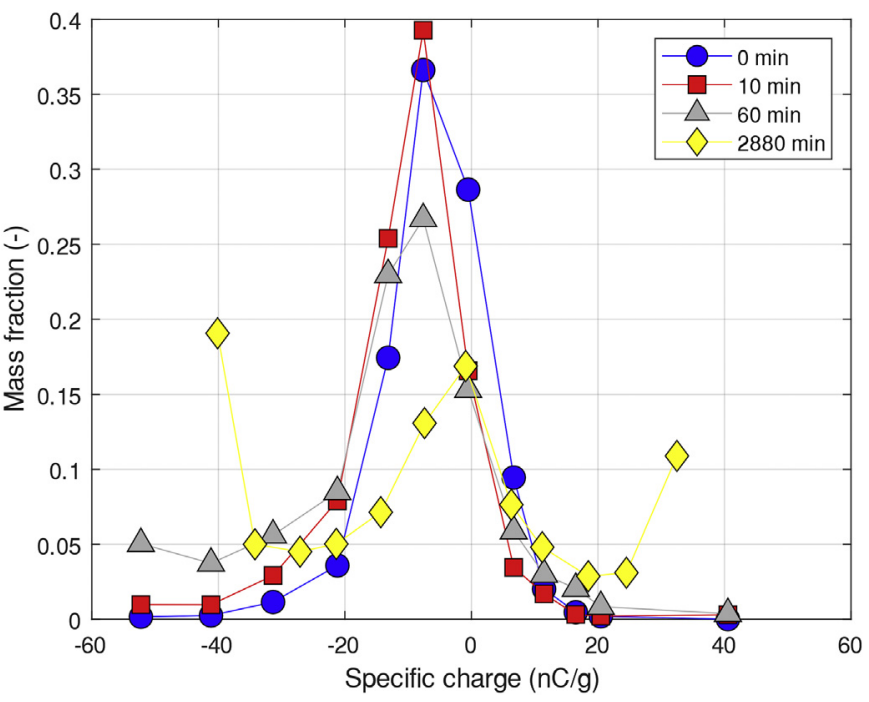

Fig. 15. The evolution of charge distribution for combined $\mathrm{P}-\mathrm{W}$ and $\mathrm{P}-\mathrm{P}$ charging for the particulate system with a narrow PSD

60 min of charging started to foul the metal walls and the rest of the particles, that collided in the bulk of the system, behaved as a system with $\mathrm{P}-\mathrm{P}$ charging only. Our results show that models which consider only the propagation of unipolar charge from wall particles towards the particulate bulk without considering the bipolar same-material P-P charging should be reviewed and this seems to be especially relevant for the cases where the system walls are fouled by insulator particles.

In analogous experiments with a broad PSD (see Table 1), $30 \mathrm{~g}$ of particles were poured into 12 compartments of the charging box $(\varphi=$ $\left.0.286, \theta_{P P / P W}=15.84\right)$. Contrary to the particulate system with a narrow PSD, the system with a broad PSD exhibited bipolar charging already after 60 min of charging (Fig. 16). However, the significant bipolar charging was observed only for particles with the diameter smaller than $0.8 \mathrm{~mm}$. Particles bigger than that behaved similarly to the system of narrow PSD (Fig. 15).

\section{5. $P-P$ and $P-W$ charging dynamics in a sequence}

In the next experiment, $10 \mathrm{~g}$ of sample with narrow PSD were alternately charged in the diluted system, i.e., in the charging box without inner walls $\left(\varphi=0.025, \theta_{P P / P W}=5.57\right)$, corresponding to $\mathrm{P}-\mathrm{W}$ charging and in 8 compartments of the box with glued particles on the inner walls $\left(\varphi=0.200, \theta_{P P / P W} \rightarrow \infty\right)$ corresponding to P-P charging, respectively. The charge distribution of the sample was measured after each charging step. Fig. 18 shows that the sample was first quickly (in 60 min) charged due to $\mathrm{P}-\mathrm{W}$ collisions to the almost uniform negative charge. After that, the sample was charged by $\mathrm{P}-\mathrm{P}$ collisions. Surprisingly, already after 10 min of $\mathrm{P}-\mathrm{P}$ charging, the previously obtained net charge was gone. We suspect that the excess charge was transferred to the ground, as the charging box was grounded. After further charging of the sample due to $\mathrm{P}-\mathrm{P}$ collisions for $24 \mathrm{~h}$, the sample was bipolarly charged. Finally, after an additional 75 min of charging due to P-W collisions, we reached the saturation charge. It appears that the charging process reflects its environment in the sense of the excess of the same-material objects or the excess of the different-material walls quickly. However, the observed surprisingly high discharge rate in one case still lacks a better understanding and will be a part of our future studies. Let us note that similar fast change in the charge was observed also by Jantač et al. [40] after the change of humidity followed up by tribocharging. 
a) uncharged

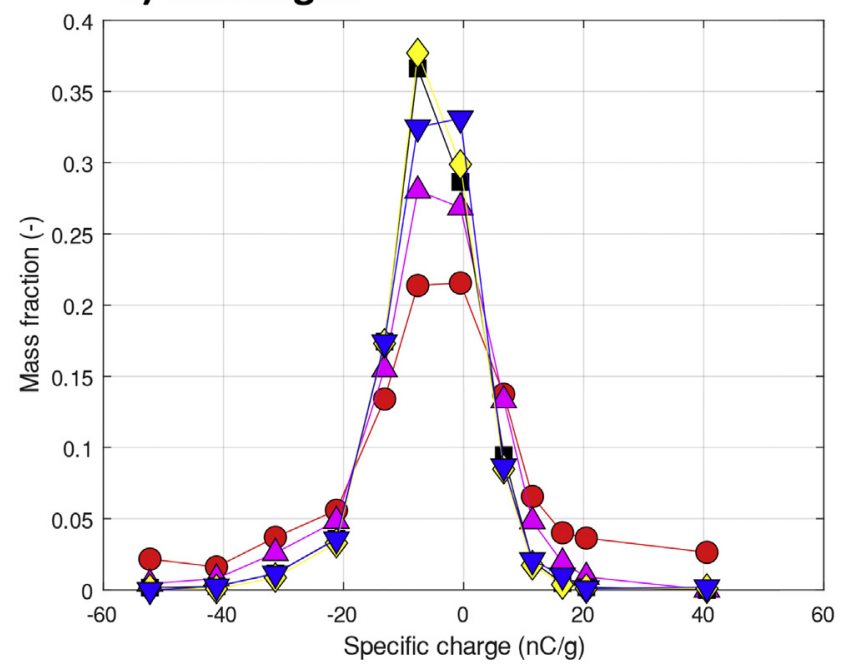

c)

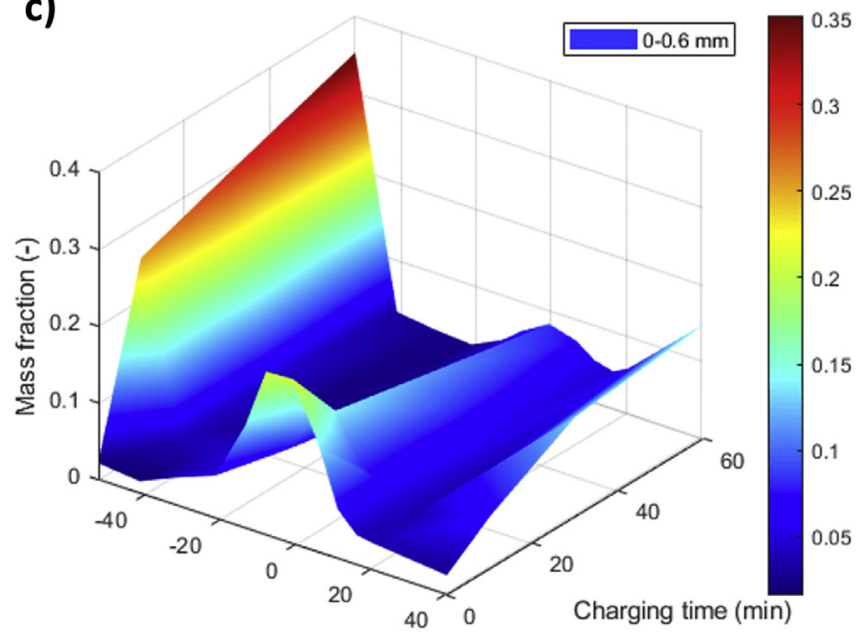

Specific charge $(\mathrm{nC} / \mathrm{g})$ b) $60 \mathrm{~min}$
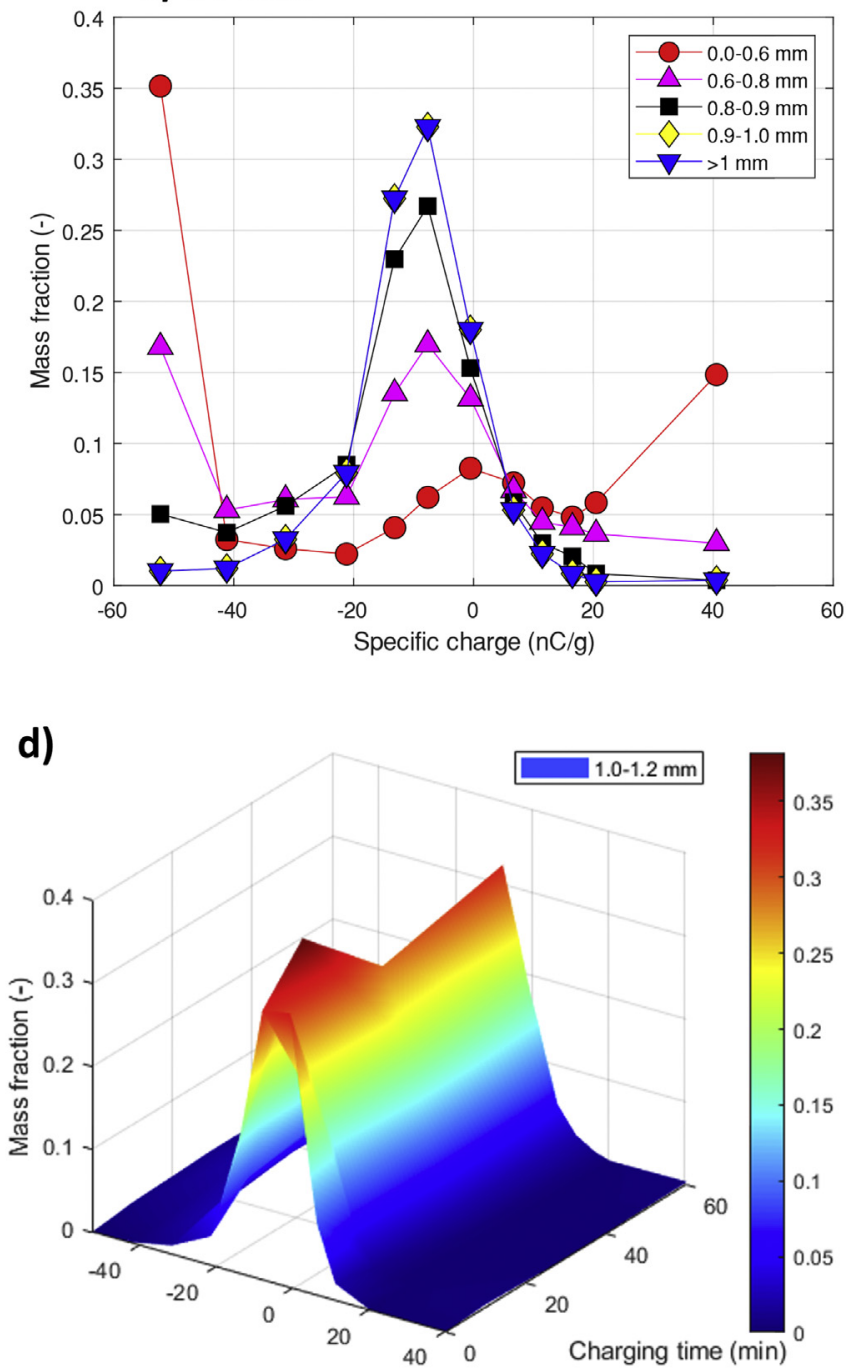

Specific charge $(\mathrm{nC} / \mathrm{g})$

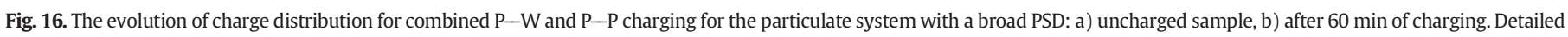
charging dynamics for $\mathrm{c}$ ) smallest fraction $(0-0.6 \mathrm{~mm})$ and d) largest fraction (1.0-1.2 mm).

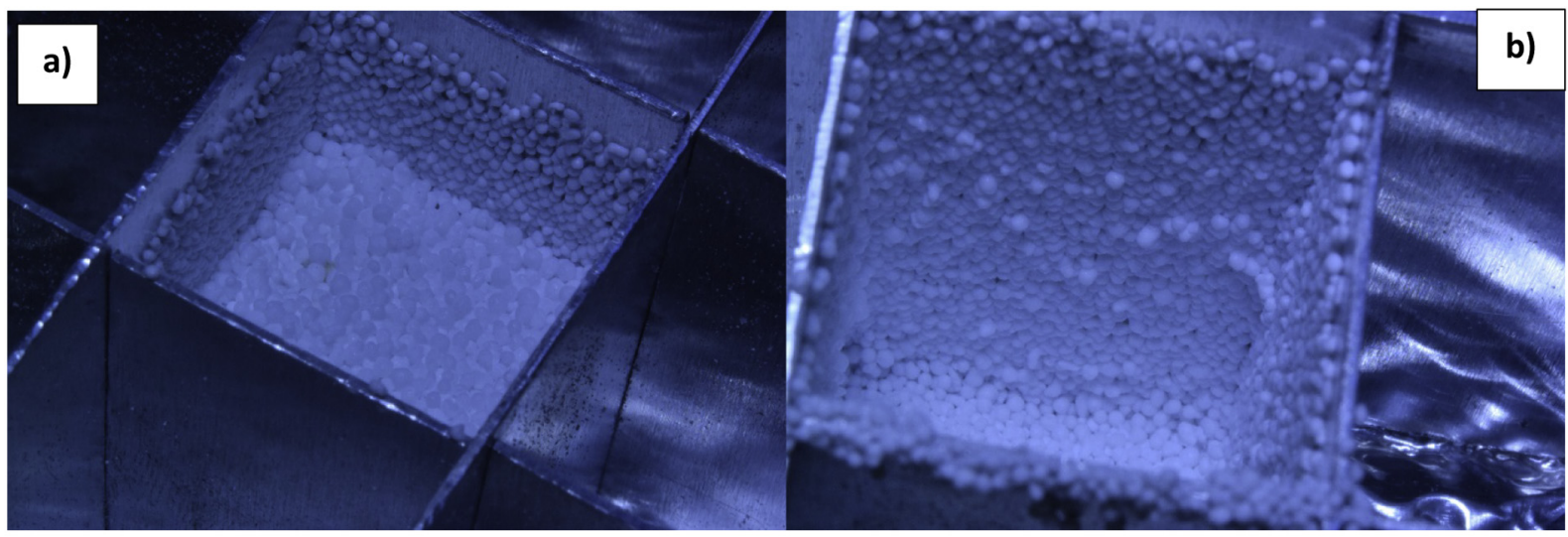

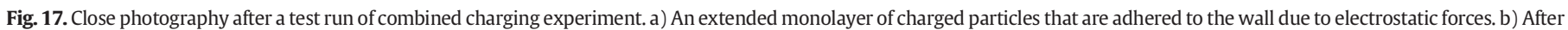

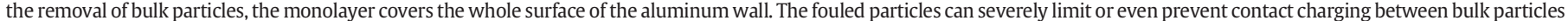
and the aluminum wall. 


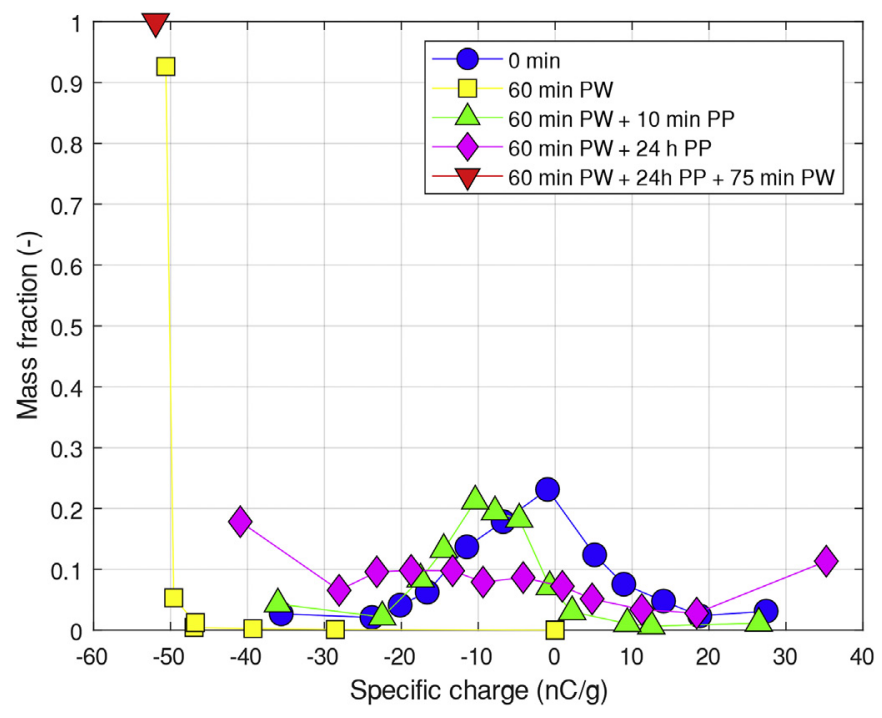

Fig. 18. The evolution of charge distribution for the sequence of $\mathrm{P}-\mathrm{W}$ and $\mathrm{P}-\mathrm{P}$ charging.

\section{Conclusions}

The electrostatic charging of PE powders due to the collisions of the powder particles with other such particles or with a metal wall was studied by means of systematic series of experiments complemented by simple mathematical models. Our aim was to identify the characteristics of $\mathrm{P}-\mathrm{W}$ and $\mathrm{P}-\mathrm{P}$ charging in isolation, simultaneously and subsequently, in order to understand the role of each of these effects in the total charge build-up in systems, where both these types of charging take place.

- First, the charge generated primarily by $\mathrm{P}-\mathrm{W}$ and $\mathrm{P}-\mathrm{P}$ collisions, respectively, was measured. Then, the simultaneous and subsequent combination of both types of the charging, respectively, followed. Our particulate mathematical model assisted us in approximate identification of the $\mathrm{P}-\mathrm{P}$ and $\mathrm{P}-\mathrm{W}$ collision frequencies in the beginning of the experiments, when electrostatic forces were insignificant.

- $\mathrm{P}-\mathrm{W}$ charging led to the subsequent narrowing of charge distribution of the PE sample and was characterized as a fast, unipolar charging that resulted in unipolar (negative) particle charge of a narrow distribution in the saturated state. The charging was examined for a system of a narrow PSD of $0.8 \mathrm{~mm}$ to $1 \mathrm{~mm}$ in diameter and the saturation in such system was reached in 60 to $75 \mathrm{~min}$.

- For P-P charging, a relatively slow and bipolar charging was observed for the narrow PSD of $0.8 \mathrm{~mm}$ to $1 \mathrm{~mm}$, as the saturation charge was reached on the time scale of 1000 to $10,000 \mathrm{~min}$.

- In a system of a nascent "broad" PSD of 0-1.2 mm that involved relatively frequent $\mathrm{P}-\mathrm{P}$ collisions, the fines up to $0.6 \mathrm{~mm}$ in diameter charged to the saturation charge quickly, i.e. within $60 \mathrm{~min}$.

- The investigation of simultaneous $\mathrm{P}-\mathrm{W}$ and $\mathrm{P}-\mathrm{P}$ charging showed that although part of the sample was charged relatively quickly (within $60 \mathrm{~min}$ ) to the charge of the negative sign, the bipolar charging dominated in the long run, i.e., after almost 3000 min of charging. Possibly, the particles near walls charged to the negative sign relatively quickly and thereafter adhered to the metal wall by the effect of electrostatic induction and prevented thus other particles from colliding with the metal walls. Such behavior is supported not only by our measurements of the evolution of the charge distribution, but is also documented by photos.

Our results regarding charging rates i.e. the fact the PE particles charged faster against wall then other PE particles are supported by the simple theory considering triboelectric series and stating that the more the two objects in contact differ in their electric properties due to the difference in a material they are made of (such as work function), the faster is their charging. In other words, it appears that the material of the objects in the contact affects their charging more significantly than the inhomogeneities of their surfaces and variations in their geometry.

Our observations imply that the frequently encountered industrial problem of fouling of metal walls by a monolayer of dielectric powders is associated with different-material $\mathrm{P}-\mathrm{W}$ charging because the particles in this setup are charged rapidly to only one polarity and attracted towards the metal walls by means of electrostatic induction. On the other hand, $\mathrm{P}-\mathrm{P}$ charging is likely to be responsible for particle agglomeration as well as for the formation of multiple-layer wall-sheets, because it results in bipolarity in the particle charge distribution.

Although our results suggest that the same-material $\mathrm{P}-\mathrm{P}$ charging is much slower than the different-material $\mathrm{P}-\mathrm{W}$ charging, they also show that the rate of charging and the character of distribution of charge 'generated' in a system is strongly dependent on the $\mathrm{P}-\mathrm{P}$ and $\mathrm{P}-\mathrm{W}$ collision frequency ratio and also on the PSD. Although the $\mathrm{P}-\mathrm{P}$ charging is several times slower than $\mathrm{P}-\mathrm{W}$ charging, even in a system with relatively low $\mathrm{P}-\mathrm{P}$ to $\mathrm{P}-\mathrm{W}$ collision ratio, some particles can form a monolayer and prevent further $\mathrm{P}-\mathrm{W}$ charging and therefore dominantly $\mathrm{P}-\mathrm{P}$ charging occurs after the formation of a monolayer, which results in an unevenly bipolarly charged system.

The subsequent charging experiments showed that the sign and the magnitude of charge on PE particles can be rapidly changed with the change of a counter-material. We plan to follow up and investigate this effect in detail in the future.

\section{Declaration of Competing Interest}

The authors declare that they have no known competing financial interests or personal relationships that could have appeared to influence the work reported in this paper.

\section{Acknowledgements}

The supports of Czech Grant Agency(Grantová Agentura České Republiky) (project GA16-07898S) and specific university research MSMT(Ministerstvo Školství, Mládeže a Tělovýchovy) (No. 21-SVV/ 2019) are gratefully acknowledged.

\section{References}

[1] L.B. Schein, Recent advances in our understanding of toner charging, J. Electrost. 46 (1) (1999) 29-36.

[2] S. Trigwell, K. Tennal, M.K. Mazumder, D. Lindquist, Precombustion cleaning of coal by triboelectric separation of minerals, Part. Sci. Technol. 21 (2003) 353-364.

[3] J. Wei, M.J. Realff, Design and optimization of free-fall electrostatic separators for plastics recycling, AICHE J. 49 (12) (2003) 3138-3149.

[4] G. Wu, J. Li, Z. Xu, Triboelectrostatic separation for granular plastic waste recycling: a review, Waste Manag. 33 (3) (2013) 585-597.

[5] H. Grosshans, M.V. Papalexandris, Large Eddy simulation of triboelectric charging in pneumatic powder transport, Powder Technol. 301 (2016) 1008-1015.

[6] H. Grosshans, L. Villafañe, A. Bankob, M.V. Papalexandris, Case study on the influence of electrostatic charges on particle concentration in turbulent duct flows, Powder Technol. 357 (2019) 46-53.

[7] M. Taghavivand, B. Elchamaa, A. Sowinski, P. Mehrani, Study of electrostatic charging of single particles during pneumatic conveying, Powder Technol. 355 (2019) $242-250$.

[8] F.J. Wang, J.X. Zhu, J.M. Beeckmans, Pressure gradient and particle adhesion in the pneumatic transport of cohesive fine powders, Int. J. Multiphase Flow 26 (2) (2000) 245-265.

[9] G.E. Klinzing, Clustering under the influence of electrostatic forces, Int. J. Multiphase Flow 12 (5) (1986) 853-857.

[10] G. Hendrickson, Electrostatics and gas phase fluidized bed polymerization reactor wall sheeting, Chem. Eng. Sci. 61 (4) (2006) 1041-1064.

[11] F. Fotovat, X.T. Bi, J.R. Grace, A perspective on electrostatics in gas-solid fluidized beds: challenges and future research needs, Powder Technol. 329 (2018) 65-75.

[12] A. Giffin, P. Mehrani, Effect of gas relative humidity on reactor wall fouling generated due to bed electrification in gas-solid fluidized beds, Powder Technol. 235 (2013) 368-375. 
[13] D. Song. P. Mehrani, Comparison of electrostatic charge generation in gas-solid fluidized beds in turbulent versus pre-turbulent flow regime, Powder Technol. 319 (2017) 426-433.

[14] D. Song, F. Salama, J. Matta, P. Mehrani, Implementation of faraday cup electrostatic charge measurement technique in high-pressure gas-solid fluidized beds at pilotscale, Powder Technol. 290 (2016) 21-26.

[15] T.A.D.L. Burgo, C.A. Rezende, S. Bertazzo, A. Galembeck, F. Galembeck, Electric potential decay on polyethylene: role of atmospheric water on electric charge build-up and dissipation, J. Electrost. 69 (4) (2011) 401-409.

[16] P.M. Ireland, Triboelectrification of particulate flows on surfaces: part I - experiments, Powder Technol. 198 (2) (2010) 189-198.

[17] P. Mehrani, H.T. Bi, J.R. Grace, Bench-scale tests to determine mechanisms of charge generation due to particle-particle and particle-wall contact in binary systems of fine and coarse particles, Powder Technol. 173 (2) (2007) 73-81.

[18] P. Mehrani, H.T. Bi, J.R. Grace, Electrostatic behavior of different fines added to a faraday cup fluidized bed, J. Electrost. 65 (1) (2007) 1-10.

[19] D. Song, P. Mehrani, Mechanism of particle build-up on gas-solid fluidization column wall due to electrostatic charge generation, Powder Technol. 316 (2017) 166-170.

[20] F. Salama, A. Sowinski, K. Atieh, P. Mehrani, Investigation of electrostatic charge distribution within the reactor wall fouling and bulk regions of a gas-solid fluidized bed, J. Electrost. 71 (1) (2013) 21-27.

[21] F. Chowdhury, A. Sowinski, M. Ray, A. Passalacqua, P. Mehrani, Charge generation and saturation on polymer particles due to single and repeated particle-metal contacts, J. Electrost. 91 (2018) 9-15.

[22] M. Ray, F. Chowdhury, A. Sowinski, P. Mehrani, A. Passalacqua, An Euler-Euler model for mono-dispersed gas-particle flows incorporating electrostatic charging due to particle-wall and particle-particle collisions, Chem. Eng. Sci. 197 (2019) 327-344.

[23] J. Kolehmainen, A. Ozel, S. Sundaresan, Eulerian modelling of gas-solid flows with triboelectric charging, J. Fluid Mech. 848 (2018) 340-369.

[24] J.C. Laurentie, P. Traoré, L. Dascalescu, Discrete element modeling of triboelectric charging of insulating materials in vibrated granular beds, J. Electrost. 71 (6) (2013) 951-957.

[25] E. Németh, V. Albrecht, G. Schubert, F. Simon, Polymer tribo-electric charging: dependence on thermodynamic surface properties and relative humidity, J. Electrost 58 (1) (2003) 3-16.
[26] N.D. Lang, W. Khon, Theory of metal surfaces: work function, Phys. Rev. B 3 (4) (1971) 1215-1223.

[27] W. Greason, Investigation of a test methodology for Triboelectrification, J. Electrost. 49 (2000) 245-256.

[28] S. Mamadou, E. Crase, J. Rajot, R. Sankaran, D. Lacks, Electrification of particles in dust storms: field measurements during the monsoon period in Niger, Atmos. Res. 102 (2011) 343-350.

[29] A. Sowinski, L. Miller, P. Mehrani, Investigation of electrostatic charge distribution in gas-solid fluidized beds, Chem. Eng. Sci. 65 (2010) 2771-2781.

[30] F. Sharmene Ali, M. Adnan Ali, R. Ayesha Ali, I.I. Inculet, Minority charge separation in falling particles with bipolar charge, J. Electrost. 45 (2) (1998) 139-155.

[31] K. Forward, D. Lacks, R. Sankaran, Charge segregation depends on particle size in Triboelectrically charged granular materials, Phys. Rev. Lett. 102 (2009), 028001.

[32] D.J. Lacks, R. Mohan Sankaran, Contact electrification of insulating materials, J. Phys. D. Appl. Phys. 44 (45) (2011) 453001

[33] L. Konopka, J. Kosek, Discrete element modeling of electrostatic charging of polyethylene powder particles, J. Electrost. 87 (2017) 150-157.

[34] D.J. Lacks, The unpredictability of electrostatic charging, Angew. Chem. Int. Ed. 51 (28) (2012) 6822-6823.

[35] H.A. Mizes, E.M. Conwell, D.P. Salamida, Direct observation of ion transfer in contact charging between a metal and a polymer, Appl. Phys. Lett. 56 (16) (1990) 1597-1599.

[36] J. Lowell, A.C. Rose-Innes, Contact electrification, Adv. Phys. 29 (6) (1980) 947-1023.

[37] N. Duff, D.J. Lacks, Particle dynamics simulations of triboelectric charging in granular insulator systems, J. Electrost. 66 (1) (2008) 51-57.

[38] M.P. Allen, D.J. Tildesley, Computer Simulation of Liquids, 385, Oxford University Press, Oxford, United Kingdom, 1989.

[39] S. Matsusaka, M. Ghadiri, H. Masuda, Electrification of an elastic sphere by repeated impacts on a metal plate, J. Phys. D. Appl. Phys. 33 (18) (2000) 2311-2319.

[40] S. Jantač, L. Konopka, J. Kosek, Experimental study of triboelectric charging of polyethylene powders: effect of humidity, impact velocity and temperature, Adv. Powder Technol. 30 (2018). 